\title{
REFLEXIONES ACERCA DEL IMPUESTO SOBRE EL CARBONO COMO INCENTIVO DE MERCADO EN EL CONTEXTO ACTUAL DE CRISIS
}

\author{
Cristina García Fernández \\ Universidad Complutense de Madrid
}

http://dx.doi.org/10.5209/rev_NOMA.2013.v37.n1.42563

\begin{abstract}
Resumen.- La finalidad de este trabajo es discutir, desde un marco teórico, las políticas económicas más efectivas que pueden emplearse en frenar los impactos del cambio climático. Con este fin se analiza el caso del impuesto sobre el carbono, por ser el incentivo que logra una mayor eficiencia en el mercado y por constituir una opción eficaz como paliativo de los efectos tan negativos que está causando la actual crisis económica mundial.
\end{abstract}

Palabras clave.- impuestos sobre el carbono; eficiencia energética

\section{Some considerations about the carbon tax as a market incentive in the present global crisis}

\begin{abstract}
The purpose of this paper is the discussion, in a theoretic frame, of the most effective economic policies that could be employed to slow the impacts of climate change. Our aim is then to analyze the carbon tax for being the economic incentive that most fulfils the efficiency objectives in the market. It is also an effective option to ameliorate the negative impacts of the present economic crisis.
\end{abstract}

Keywords.- carbon taxes; energy efficiency

JEL classification: H41, Q51, Q54

\section{Introducción}

Hoy en día, disponemos de diversas políticas económicas de tipo preventivo destinadas a reducir las emisiones de gases de efecto invernadero. La literatura existente suele definir a estas políticas como coste-eficientes ya que pueden (Clarke, $\mathrm{R}$ el al, 1996) lograr una reducción importante de emisiones sin tener que incurrir en un coste muy alto. Del mismo modo, estas políticas también son coste efectivas siempre que no sólo consigan recortes importantes de emisiones del gas mayormente emitido a la atmósfera, sino también de otros gases de efecto invernadero. Por ejemplo, aumentar la eficiencia energética no sólo reduce las emisiones de dióxido de carbono sino también de otros gases que contribuyen altamente al calentamiento global. Pero además, una mayor eficiencia puede hacer que las industrias y los países se tornen más competitivos en los mercados internacionales. Ahora bien, las políticas económicas destinadas a mejorar la eficiencia energética, para que sean efectivas, necesitan el apoyo del público y de los grupos de interés, esto es, los 
gobiernos no pueden ser los únicos que tomen partido en el recorte de las emisiones, también es necesaria la colaboración de los individuos, comunidades, empresas y países. La educación y la concienciación de los ciudadanos favorecen el consumo eficiente de energía y, por tanto, la sustitución de combustibles fósiles por otros que eviten la excesiva explotación de los recursos. Por tanto, podemos afirmar que las políticas económicas preventivas constituyen el núcleo de medidas fundamentales para evitar el avance del calentamiento global.

El impuesto sobre el carbono constituye una opción eficiente como medida paliativa de cambio climático ya que es capaz de conseguir reducciones de emisiones sin incurrir en costes excesivos. Sin duda esta es una gran ventaja. Además, este instrumento bien gestionado puede ser un incentivo para lidiar con algunos de los problemas económicos que nos ha traído la crisis económica internacional.

\section{Las políticas económicas de cambio climático}

Las políticas económicas preventivas destinadas a paliar el calentamiento global tienen dos objetivos prioritarios: reducir las emisiones de los gases invernadero y crear sumideros.

La opción de adoptar una acción preventiva depende de cómo sea la relación entre los costes de reducir las emisiones de gases invernadero y los daños que estos gases pueden ocasionar si no son sometidos a ningún control. La creación de sumideros constituye una de las medidas prioritarias. La pérdida de los bosques naturales del mundo contribuye más a las emisiones globales anuales que el propio sector del transporte. Toda reducción en la despoblación forestal es un método altamente rentable de reducir las emisiones de carbono.

Los mecanismos fundamentales para conseguir dichos objetivos pasan por incrementar la eficiencia energética, disminuir la producción y consumo de combustibles fósiles, sustituir los combustibles fósiles por otros menos contaminantes, fomentar el cambio tecnológico y acelerar la reforestación como sumidero primordial.

Los instrumentos económicos más eficientes son aquellos que introducen diferentes incentivos para poder conseguir niveles de emisiones más reducidos, alterando, para ello, el sistema de precios. Por ello, también se les conoce como incentivos económicos o de mercado. El objetivo consiste en alterar el sistema de precios para disminuir o modificar las actividades económicas que puedan resultar nocivas para el medio natural. No obstante, todavía son las regulaciones administrativas las medidas que constituyen la mayor parte de las medidas de protección del medio ambiente. Estas no son expresamente incentivos económicos y, por tanto, no suelen alterar el sistema de precios. En general, son más costosas y menos eficientes que los incentivos ${ }^{1}$.

1 Una revisión de la teoría sobre los incentivos económicos puede encontrarse en García, C (2008). 
Así pues, la respuesta prudente al cambio climático radica en una combinación de políticas económicas que consigan mejoras en la eficiencia energética. La prevención constituye una alternativa eficiente para adaptarse al cambio climático incurriendo en menores riesgos y propiciando el desarrollo sostenible.

Por otro lado, hay que tener en cuenta que la adopción de medidas preventivas no sólo está justificada por el riesgo que se evita, sino que también es necesario que estas tengan un punto de partida efectivo. La adopción de medidas graduales es importante, ya que de otro modo podríamos incurrir en costes prematuros (de transición o ajuste) excesivamente altos o innecesarios. Así pues, las políticas deben ser efectivas desde su puesta en marcha a la vez que adaptables a las necesidades del momento. Por ejemplo, si establecemos un impuesto sobre el carbono, este no debe partir de una tasa excesivamente alta, ya que no dejaríamos tiempo para que los mercados y los equipos se adapten a los nuevos cambios de los precios -o tendrían que hacerlo incurriendo en un coste excesivo, perdiendo así el objetivo de eficiencia. -. Pero tampoco es conveniente mantener la misma tasa a largo plazo, ya que, factores como el aumento de la población y, en consecuencia, la mayor demanda de energía pueden requerir tasas impositivas mayores con el fin de evitar emisiones más cuantiosas.

También puede ocurrir que el desarrollo y puesta en marcha de nuevas tecnologías energéticas eficientes sea más rápido de lo previsto facilitando la reducción del impuesto. La disponibilidad de nuevas tecnologías que no emitan carbono es un prerrequisito, aunque no una garantía, para reducir las emisiones de carbono a un coste razonable. El recorte de las emisiones depende también de que se reduzcan las barreras que existen en la actualidad para la difusión y transferencia de tecnología, de la movilización de recursos financieros, del apoyo a los países en desarrollo, etc. Además, la combinación óptima de políticas puede variar de un país a otro, dependiendo de factores como la estructura de los mercados de energía, de la configuración política, de la receptividad de la sociedad, etc.

Por último, cuando hablamos del coste de los instrumentos económicos solemos referirnos al coste económico medido en términos de pérdida de producción o bienestar producidos por las restricciones que estos instrumentos conllevan. De otra manera sería imposible llevar a cabo una reducción de emisiones. Pero además, existen otro tipo de costes que son los que genera la propia gestión y control del instrumento. Cada instrumento económico requiere un control y un seguimiento diferente, ya que para que cumplan bien su cometido tienen que estar bien diseñados y gestionados. Por todo esto, y, debido a que el control es costoso ( $y$, a veces imposible) este es un aspecto a tener en cuenta para elegir entre un instrumento $u$ otro.

\section{El instrumento más adecuado en el contexto de crisis económica}

La utilización de instrumentos económicos en las políticas ambientales permite el cumplimiento de los objetivos ambientales a mínimo coste (eficiencia 
estática), a la vez que introduce incentivos para una mejora ambiental continua (eficiencia dinámica) ${ }^{2}$. Teniendo en cuenta que esto es cierto para cualquier problema ambiental en el que exista un gran número de contaminadores de distinta índole y procedencia, en el caso del cambio climático es todavía más importante. Esto es debido, en primer lugar, a que hay muchos contaminadores heterogéneos (prácticamente todos los agentes económicos contaminan), procedentes de distintos sectores económicos que generan emisiones dispares, muchas relacionadas con la obsolescencia tecnológica. En segundo lugar, porque los costes asociados a la reducción de emisiones son potencialmente tan elevados que es esencial intentar conseguir las ganancias de eficiencia estática y dinámica.

El problema del coste ha sido y sigue siendo una de las cuestiones cruciales a la hora de utilizar los instrumentos económicos en el ámbito del cambio climático. No deja de ser lógico que los economistas tratemos de encontrar alternativas eficientes que no sólo prevengan y actúen sobre el control de las emisiones, sino que además estos controles no resulten excesivamente caros. Es por ello que el objetivo primordial de cualquier política destinada a paliar los efectos nocivos de la contaminación ambiental (en concreto la atmosférica) es que ésta sea coste-eficiente, esto es, que pueda obtenerse la reducción máxima de emisiones para un nivel dado de gasto.

En general, los economistas tendemos a afirmar que una combinación de políticas suele ser la mejor opción, ya que la utilización de un instrumento u otro va a depender de diversos factores en cada momento. No obstante, y tras haber comparado en distintos trabajos ${ }^{3}$ varios instrumentos económicos, en concreto, sistemas de regulación pura, mercados de emisiones e impuestos sobre el carbono podemos concluir que el impuesto sobre el carbono tiene una triple ventaja sobre la utilización de otros incentivos:

1. Por lo general, un impuesto sobre las emisiones ofrece incentivos más fuertes para desarrollar y aplicar nuevas y más limpias tecnologías que una política basada en el control cuantitativo de las mismas, esto es, su eficiencia dinámica es mayor.

2. El impuesto es capaz de conseguir un recorte neto de las emisiones de carbono, ya que las empresas, con el fin de reducir la cuantía del impuesto, tendrán un incentivo adicional para reducir sus emisiones.

3. El impuesto es preferible al sistema de permisos de emisiones ya que dicho sistema ofrece un resultado que depende de la asignación inicial de los permisos (que tiene consecuencias en cuanto a su distribución) y de las variaciones del precio (los permisos establecen un precio por unidad o tonelada de carbono), (Paltsev, el al, 2005). Esto es relevante ya que la fluctuación del

${ }^{2}$ Eficiencia estática. Este criterio hace referencia al coste de lograr una mejora ambiental determinada mediante la aplicación de un instrumento específico. Cuanto más bajo sea el coste, más atractivo será el instrumento. Eficiencia dinámica. Este criterio se refiere a la adecuación que tiene un instrumento para resolver cambios no previstos y para crear incentivos que conduzcan al desarrollo de nuevas y mejores soluciones técnicas capaces de solventar los problemas ambientales.

3 Para un análisis comparativo de los distintos instrumentos económicos desde el punto de vista de la eficiencia consultar (García, C; 2008, 2009, 2010 y 2013). 
precio del carbono hace difícil estimar el coste total que conllevarían los permisos de emisión. En general, los permisos de emisiones generan mayores incentivos para el desarrollo tecnológico que los sistemas de regulación pura pero, en numerosas ocasiones, constituyen un incentivo más débil que los impuestos sobre el carbono. La explicación es sencilla. Si varias empresas adoptan nuevas tecnologías, la demanda total de permisos caerá y también su precio. Entonces disminuirá la rentabilidad de haber adoptado la nueva tecnología y con ella los incentivos para desarrollar nuevos métodos de producción. En este último caso es preferible el impuesto.

Los instrumentos de mercado siempre han sido y son una herramienta muy utilizada por los economistas del medio ambiente ya que tienen una aplicación muy directa para la mayor parte de los problemas medioambientales. El cambio climático constituye uno de los aspectos más urgentes como problema medioambiental y como externalidad ambiental en sí mismo. Hoy en día, en el contexto de crisis económica en el que nos encontramos los incentivos de mercado cobran un interés aún mayor ya que algunos son claramente mecanismos de intervención pública, caso del impuesto sobre el carbono, pudiendo conseguir, desde el punto de vista del coste, condiciones de eficiencia muy interesantes (eficiencia estática y dinámica). Ya sabemos que el impuesto sobre el carbono fomenta la eficiencia dinámica, esto es, el desarrollo de tecnologías energéticas más eficientes y limpias. Además, en el contexto de crisis en el que estamos, cada vez van a ser más necesarios para contrarrestar el posible aumento de la demanda de CF, en particular, la del carbón por sus precios moderados y las grandes reservas existentes, la del petróleo, por sus reservas abundantes y, la del gas natural, por ser hoy en día una fuente de energía alternativa a los CF más contaminantes. Por último, como apunta Labandería $(2011)^{4}$, si conseguimos mantener los precios de los productos energéticos, a través de instrumentos de mercado, ello conllevará mejoras en eficiencia energética, reduciendo así la vulnerabilidad y dependencia externa. También se consigue a través de estos instrumentos una menor exportación de rentas, captadas parcialmente a través del instrumento de mercado por el país consumidor.

\section{Necesidad de un cambio en el modelo productivo}

Actualmente, los precios de los combustibles fósiles están iniciando una escalada (excepto el carbón) después de la caída que experimentaron al comienzo de la crisis (2008). La bajada del precio durante los primeros dos años de la crisis pareció constituir un incentivo para una menor extracción y consumo de los mismos. Aunque la recesión trajo consigo una caída en general del consumo de energía (sobre todo el sector eléctrico) por la caída del PIB (ver gráfico 1), dicha tendencia se ha ido moderando. En general, las previsiones apuntan a que el carbón y el gas natural seguirán dominando la generación eléctrica (sector que produce las mayores emisiones de CO2),

4 GAGO, A; LABANDEIRA, X. "Cambio climático. Impuestos y Reformas Fiscales". Estudios de Economía Política, 19 (2011):147-161. 
aunque sus cuotas conjuntas se reducirán de forma importante en los países de la OCDE por la expansión de las energías renovables y de la energía nuclear. Sin embargo, en Asia y América del Norte todo apunta a que la demanda de combustibles fósiles, el carbón en particular, seguirá en aumento. También en la mayor parte de los países emergentes. Esto es debido a que es allí donde se encuentran las mayores reservas de este combustible.

Gráfico 1. Evolución del PIB y de la demanda eléctrica.

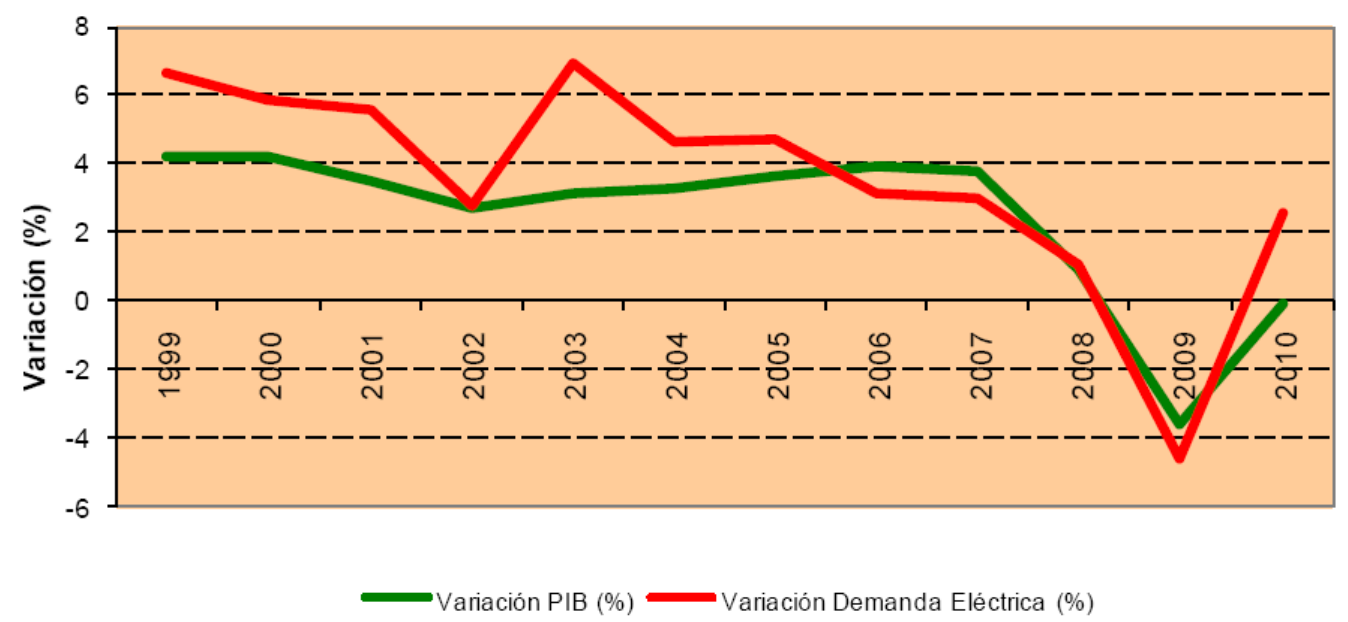

Fuente: Comisión Nacional de la Energía (2011).

El gráfico 1 muestra la correlación existente entre la evolución del PIB y la demanda de energía eléctrica. La crisis económica trajo consigo una caída de la actividad económica que produjo recortes importantes en el consumo y producción de energía. Dicha tendencia parece haberse revertido en la actualidad, donde los patrones de consumo energético han invertido, aunque no de forma completa, la tendencia mostrada en los primeros años de crisis. Algo parecido ha ocurrido con el precio de los combustibles fósiles de los que se observa una caída importante en los primeros años de crisis para después modificar esta tendencia. Las previsiones apuntan una evolución alcista con la excepción del carbón (gráfico 2). 


\section{Gráfico 2. Evolución histórica del precio de los combustibles fósiles y previsiones de futuro.}

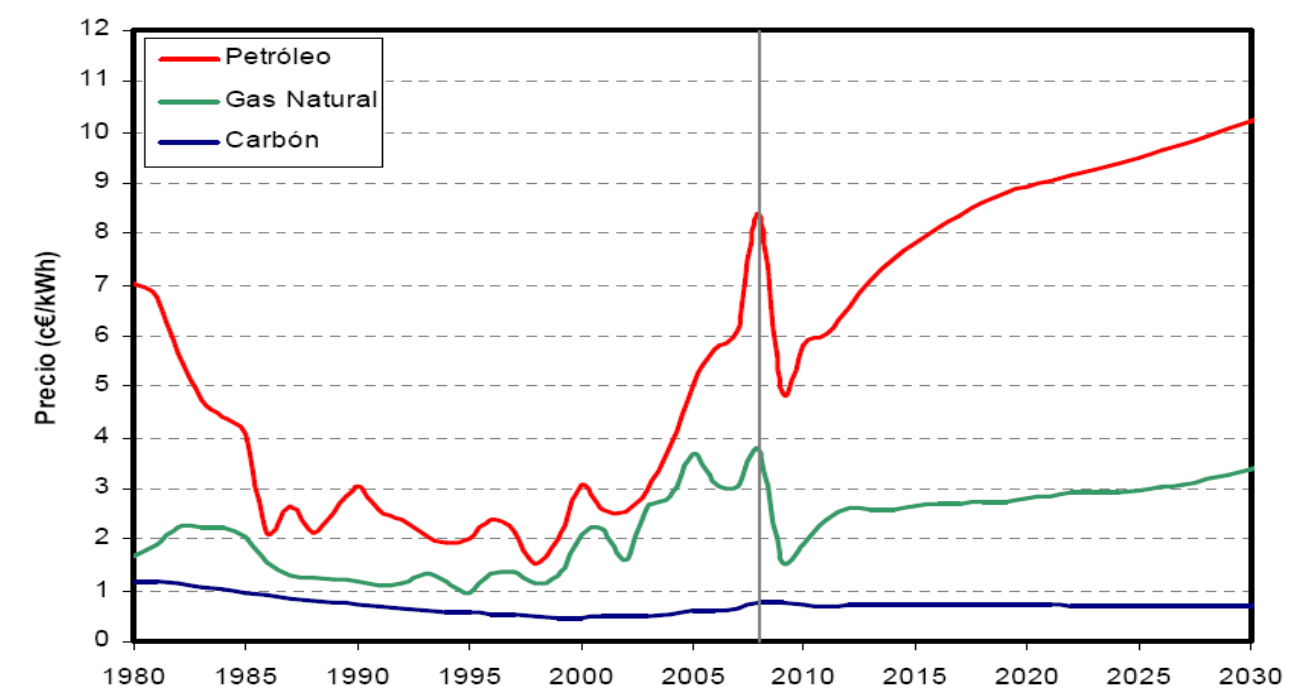

Fuente: International Energy Outlook 2011. US Department of Energy (DOE), 2011.

Como vemos en el gráfico 2 y, a diferencia del petróleo y el gas natural, el precio del carbón se mantendrá estable e incluso disminuirá ligeramente en la década de 2020. Este recurso es todavía muy abundante y se estima que hay reservas para los próximos 200 años. No se prevé que el precio de la electricidad generada mediante esta fuente de energía se incremente con el tiempo.

Gráfico 3. Consumo Mundial de Energía, 2007-2035
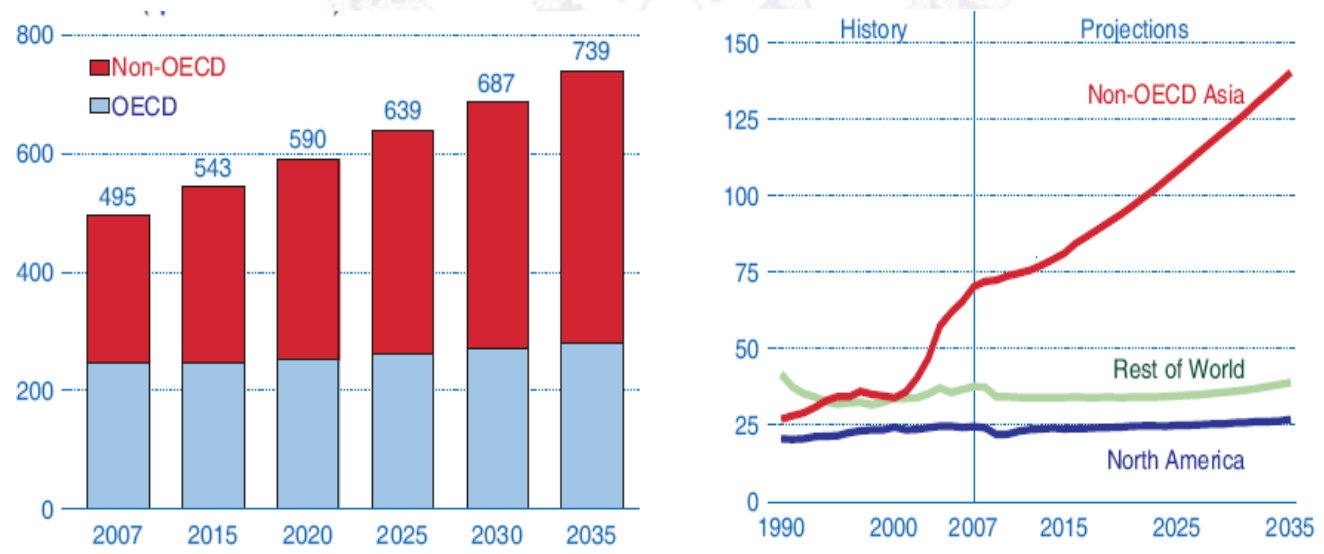

Fuente: International Energy Outlook 2011.

Según muestra el gráfico 3 , el ritmo de consumo energético para los próximos años, especialmente en los países que no pertenecen a la OCDE, no será sostenible de seguir la tendencia prevista. Los combustibles fósiles tienen un 
techo de producción y unas reservas estimadas probadas de unos 50 a 60 años para el petróleo y gas natural, y de unos 190 años para el carbón.

Sin un cambio radical de modelo energético, la previsión para 2030 es que el consumo mundial de energía sea un $60 \%$ superior al actual, con el petróleo y el carbón como fuentes de mayor consumo, y el gas natural el de mayor crecimiento, con un renovado crecimiento para la nuclear y ligero incremento de las renovables en valor absoluto (International Energy Outlook, 2011). En la primera década del siglo XXI, EE UU consumía el 25\% de la energía mundial con algo más del 4\% de la población mundial. Si esta tendencia se mantiene, en 2030 los países con mayor consumo de energía serán China (que triplicará el actual), EE UU (aumento del 70\%) e India (casi cuadruplicará). En conjunto, según el IEO (2011), el consumo de energía mundial entre 2005 y 2030 puede representar un incremento del $60 \%$.

La evolución sostenida a niveles muy bajos del precio del carbón (gráfico 2) unido a las previsiones del aumento del consumo mundial de energía (gráfico 3) nos da a entender que las emisiones de carbono seguirán aumentando. Si bien es cierto que durante los años de crisis estas han descendido, los datos sobre las previsiones indican que dichas emisiones pueden seguir aumentando en el futuro. Por tanto, con la finalidad de que esto no ocurra, unido a la emergencia de impulsar tecnologías energéticas eficientes, se torna necesario que la implementación de políticas mitigadoras en el ámbito del mercado tenga lugar de una forma generalizada e inmediata en todos los países.

Es relevante pues introducir un incentivo que cambie el sentido de este contexto. Es importante que el precio del carbón evolucione, al menos, de una forma similar a como se prevé que lo haga el petróleo y el gas natural. La introducción de un impuesto sobre el carbono incrementa el precio de los CF provocando una caída de su consumo y poniendo, además, en marcha el mecanismo de las elasticidades cruzadas (ver apartado "la cuestión de la elasticidad"). El anexo 1 muestra un estudio en el que se observa cómo un impuesto de 27 dólares por tonelada de carbono incrementa el precio del carbón y del petróleo (en menor magnitud que el del primero) provocando una caída del consumo de estos combustibles y aumentando la demanda de gas natural (elasticidad cruzada del carbón y el gas natural y del petróleo y el gas natural).

\section{El impuesto sobre el carbono. Reflexiones}

En esta parte consideramos tres cuestiones respecto al diseño del impuesto: la base, el tipo impositivo y los aspectos distributivos. También haremos una breve referencia al comercio.

La finalidad es ir delimitando cómo sería un impuesto que cumpliera, en la medida de lo posible las condiciones de optimalidad (ver Pigou 1938), o al menos, en la práctica, que consiguiera internalizar las externalidades producidas por las emisiones sin incurrir en excesivos costes administrativos. No consideraremos las cuestiones políticas tales como las concesiones que 
serían necesarias para el establecimiento del impuesto por consenso o bajo algún tipo de acuerdo.

\section{Definición}

La definición más clara de un impuesto sobre el carbono es la que realiza James Poterba (1991): "Un impuesto específico, esto es, una cantidad absoluta fija por tonelada de carbón o barril de petróleo. El impuesto está diseñado para internalizar las externalidades asociadas con el consumo de combustibles, por lo que no debería de variar ante shocks en los precios de los combustibles como lo haría un impuesto ad valorem".

El World Resources Institute (WRI), define el impuesto sobre el carbono como "un impuesto sobre los productores de combustibles fósiles (a veces también llamado energía primaria) basado en el contenido relativo de carbono de los combustibles". Los impuestos sobre el carbono son proporcionales a las emisiones de $\mathrm{CO}_{2}$ cuando el combustible se quema. Un impuesto sobre el carbono crea un incentivo para productores y consumidores: evitar pagar el impuesto reduciendo el uso de los combustibles intensivos en carbono. Contrariamente a otros productos y actividades gravadas, esta evasión del impuesto genera importantes beneficios sociales: reducción de la utilización de energía y recorte de las emisiones de $\mathrm{CO}_{2}$.

Estos razonamientos han llevado a una variedad de propuestas basadas en la idea del "Impuesto sobre el Carbono". La idea general es que el combustible debería gravarse sobre la base de la cantidad de carbono que contiene. La cantidad de carbono del combustible, unido a la cantidad de este que es utilizada, determina cuanto dióxido de carbono será emitido a la atmósfera. Los combustibles que contienen carbono difieren en el contenido de este: el carbón es el combustible que más carbono contiene, seguido del petróleo y el gas natural. Según esto, el carbón debería gravarse más fuertemente que el petróleo y este, a su vez, más que el gas natural. Los combustibles que no contienen carbono, como la energía nuclear y las fuentes de energía renovables escaparían al impuesto y constituirían opciones relativamente más atractivas económicamente.

\section{Reforma Fiscal medioambiental}

Un impuesto sobre el carbono bien diseñado puede crear beneficios medioambientales y económicos importantes. Una estrategia encaminada a establecer un impuesto doméstico sobre el carbono que sea efectivo y que capture los beneficios antes descritos debe cumplir tres requisitos generales (WRI, 1995) 5 :

1- Minimizar las pérdidas económicas que surgen a corto plazo mediante el uso eficiente de los ingresos recaudados.

5 World Resurces Institute. (1995). 
2- Maximizar los rendimientos económicos mediante la reducción de otros impuestos.

3- Compensar a los grupos afectados negativamente.

Esto es lo que hoy en día se llama Reforma Fiscal Medioambiental. Esta reforma utiliza a la imposición y otros instrumentos fiscales para captar ingresos a la vez que se beneficia al medioambiente. Para los países desarrollados los impuestos sobre el carbono pueden sustituir a otros impuestos, tales como los impuestos sobre la renta y el capital además de mejorar las condiciones económicas reduciendo la tasa de desempleo ${ }^{6}$. En los países en desarrollo, los ingresos de los impuestos sobre el carbono pueden destinarse a medidas encaminadas a paliar la pobreza tales como el desarrollo de infraestructuras o los incentivos para una industria más eficiente energéticamente. La reforma fiscal ambiental nos brinda una oportunidad para desarrollar estrategias impositivas que mitiguen el cambio climático a la vez que impulsan el crecimiento económico y el desarrollo.

En la actualidad, una reforma fiscal en la que se usen los ingresos públicos derivados de impuestos sobre el carbono para reducir otros impuestos que distorsionan y desincentivan el trabajo o el capital es especialmente necesaria para impulsar la actividad y el crecimiento económico, más aun cuando nos movemos en un contexto de de deficits públicos muy inflados. Más interesante se torna cuando no supone ninguna pérdida de recursos para el sector público. En tiempos de crisis económica, más que nunca, puede cumplirse el denominado dividendo múltiple de la imposición de los GEl: mejora ambiental, fomento de tecnologías limpias, reducción de la dependencia energética, y aumento del empleo y la actividad económica 7 .

\section{Costes y beneficios}

Comparado con un sistema de permisos de emisiones, el impuesto sobre el carbono tiene menor complejidad para los gobiernos y ofrece mayor certidumbre respecto a su coste para los contaminadores. Los gobiernos gravarán a las empresas contaminantes por cada tonelada de CO2 emitida a la atmósfera. Por tanto, el contaminador tiene un motivo para reducir las emisiones de $\mathrm{CO} 2$, que no es más que evitar el impuesto y, por tanto, puede aproximar sus costes a sus beneficios con mayor certidumbre. El impuesto es menos complejo para los gobiernos debido a que muchos países gravan desde hace tiempo a los vehículos en base a sus niveles de emisiones, lo que hace que el impuesto sobre el carbono sea un complemento de otros impuestos previamente existentes (aunque determinar el contenido de carbono no sea tan sencillo en algunas ocasiones). Esto, unido a los ingresos que se derivan del impuesto constituye importantes ventajas. Las desventajas del impuesto son,

6 La cuestión de la afectación en el empleo varía según los estudios. En el cuadro 3 de este documento se muestran resultados donde el empleo se reduce al introducir el impuesto.

7 Cambio climático. Impuestos y Reformas Fiscales. Gago, A; Labandería, X. Estudios de Economía Políitca, 19 (2011):147-161. 
sin duda, su impopularidad entre la clase política y los sectores más afectados y, la incertidumbre acerca de su efectividad en la reducción de emisiones.

Por otro lado, cualquier impuesto lleva asociado un nivel de reducción de la contaminación y, asociado a cualquier nivel de reducción de la contaminación habrá un coste, el coste de lograr la reducción marginal. No conocer el impuesto apropiado es lo mismo que no conocer el nivel apropiado de reducción de la contaminación. Hasta la fecha, se han realizado numerosas propuestas para lograr distintos niveles en la disminución de las emisiones.

El problema a la hora de establecer una meta determinada de emisiones surge cuando hay que elegir la meta efectiva. $\mathrm{Si}$, por ejemplo, establecemos una meta de reducción de emisiones podemos estar seguros acerca del nivel de emisiones pero no del coste asociado. Sin embargo, si nuestro objetivo es establecer un impuesto y no un límite cuantitativo de emisiones, podemos conocer cuanto costará reducir las emisiones en el margen, esto es, el coste marginal del impuesto - los que contaminan no gastarán más de lo que ahorrarían si no pagaran el impuesto- pero no el nivel de emisiones asociado a dicho impuesto.

Una razón para preferir el impuesto sobre el carbono es que la reducción de las emisiones dependerá no sólo de la magnitud del impuesto, sino también del precio de los combustibles fósiles, y este precio es variable. Por ejemplo, si el precio del crudo permanece alto, es posible que muchos países logren las metas de reducción de emisiones mencionadas anteriormente sin incurrir en costes adicionales, es decir, sin gastar dinero para evitar los daños potenciales del cambio climático (existen estudios que muestran la correlación existente entre el aumento del precio del crudo y la reducción de emisiones) ${ }^{8}$. Por otro lado, si los precios del crudo disminuyen hasta su niveles previos, el coste de llevar a cabo una meta cuantitativa podría volverse muy alto. Si imponemos un impuesto, podemos estar seguros de que siempre tendremos un incentivo para reducir las emisiones. Esta es una de las grandes virtudes del impuesto sobre el carbono.

Por todo ello, podemos decir que el coste total de reducir las emisiones puede ser menor caso de aplicarse una política impositiva sobre el carbono, ya que, dado que cada productor que utilice combustibles fósiles pagará el mismo impuesto, cada uno de ellos tendrá por tanto el mismo incentivo para reducir las emisiones (gráfico 4) Ahora bien, lo mismo no puede ser aplicado a otras políticas. Por ejemplo, si se aplicara un impuesto sobre el petróleo (un solo tipo de combustible fósil), los propietarios de los vehículos tendrían un mayor incentivo para reducir las emisiones que otros contaminadores, por lo que el coste de hacer frente a las reducciones de emisiones resultantes sería excesivo. En definitiva, con el impuesto sobre el carbono siempre podrían redistribuirse a los grupos más pobres las ventajas de eficiencia que supone dicho impuesto, esto es, la diferencia entre los costes de lograr un cierto nivel de reducción de emisiones con el impuesto sobre el carbono y los costes que supondría una política alternativa.

8 Metcalf y Weisbach, 2009 
Gráfico 4: Los costes de reducir las emisiones con un impuesto

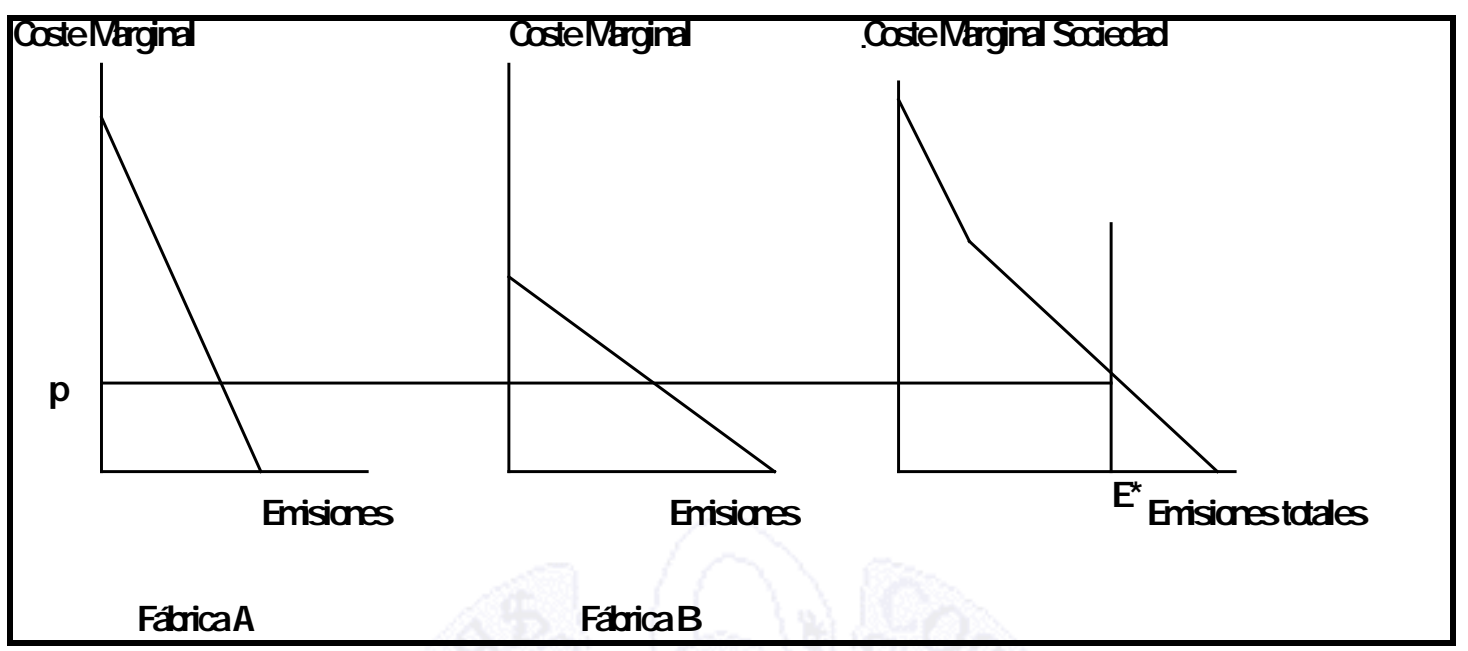

\section{Fuente: elaboración propia.}

El gráfico 4 muestra los costes de reducir las emisiones de carbono en las dos fábricas. Las emisiones se miden a lo largo del eje de accisas. Las curvas de costes marginales muestran el coste de reducir las emisiones en una unidad. Las curvas son decrecientes indicando que grandes reducciones de emisiones aumentan el coste de reducir una tonelada adicional del contaminante. Podemos gravar las emisiones con un impuesto sobre el carbono a una tasa de $p$ unidades monetarias (euros, dólares, etc.) por tonelada de carbono. Fijada una meta global en $\mathrm{E}^{*}$, cada fábrica reduciría sus emisiones hasta que el coste marginal igualara el impuesto. Cada unidad contaminante reducirá sus emisiones teniendo en cuenta sus CM pero pagarán la misma tasa por tonelada de carbono. Esto constituiría, por tanto, una política eficiente.

\section{La base del impuesto}

Para resolver esta cuestión debemos considerar primero el problema de decidir cuanto debe variar el impuesto según el combustible. Como ya hemos dicho, para que el impuesto sea eficiente este debe establecerse sobre el contenido de carbono ${ }^{9}$ - emisiones de carbono o las de $\mathrm{CO}_{2-}$, y no sobre el uso de los combustibles fósiles. También sabemos que las emisiones varían según el tipo de combustible. El carbón contamina más que el petróleo y este último más que el gas. Por lo tanto, el impuesto más alto debe imponerse sobre el carbón y el menor sobre el gas. Las fuentes de energía no fósiles, tales como la hidroeléctrica y la nuclear entre otras, no emiten $\mathrm{CO}_{2}$, por lo que no estarían sujetas a este tipo de impuesto. No obstante, estas formas de energía tienen sus propios costes medioambientales, por lo que, como regla general

9 Dado que los pesos atómicos del carbono y el oxígeno son 12 y 16 respectivamente, una tonelada de carbono equivale a 3,67 toneladas de dióxido de carbono. 
económicamente eficiente, todos los precios deberían reflejar los costes medioambientales y algunos sociales.

Una cuestión más difícil concierne a la magnitud absoluta del impuesto. ¿Qué tamaño debería tener este impuesto? La respuesta depende de que el impuesto sea el objetivo a alcanzar o no. Si el impuesto es el objetivo de una política determinada, entonces habría que preguntarse: ¿ en cuánto deberían reducirse las emisiones?. La respuesta no es fácil. Una opción sería establecer un impuesto sobre el carbono y observar la reducción de emisiones resultante, en vez de establecer una meta determinada de emisiones e intentar calcular el impuesto que sería necesario para alcanzar dicha meta, tarea que no es fácil, aunque sea el método más comúnmente utilizado.

Volviendo a la pregunta que nos planteábamos al principio sobre qué tamaño debe tener el impuesto debemos hacer algunas aclaraciones adicionales. Si el impuesto está enfocado únicamente a consideraciones medioambientales, la tasa impositiva ideal sería aquella bajo la cual los beneficios resultantes de la reducción de la última tonelada de carbono (beneficios marginales) igualaran el coste adicional resultante de la eliminación de esa tonelada (coste marginal). Como ya hemos apuntado, la teoría muchas veces no tiene correspondencia con la práctica. Lo que queremos resaltar es que ese punto de equilibrio es muy difícil de alcanzar, especialmente tratándose de beneficios que pueden manifestarse a lo largo de muchas generaciones futuras o de situaciones en las que la ciencia o los riesgos relativos no están lo suficientemente comprendidos.

En realidad, el impuesto o la política eficiente no podría calcularse realmente hasta que las emisiones fueran traducidas a concentraciones atmosféricas, ya que son las concentraciones y no el nivel de emisiones las que determinan el calentamiento de la Tierra. Tampoco podría ser calculado hasta que sean estimados los efectos de las concentraciones crecientes, esto es, el ritmo y nivel de calentamiento global; hasta que los daños ambientales y económicos asociados al aumento de la temperatura sean estimados y hasta que se valoren los daños ocasionados.

No obstante, la ausencia general de datos formales sobre impactos medioambientales no impide que se desarrollen programas destinados a reducir los riesgos. Los impuestos medioambientales, cuya aplicación es cada vez más amplia en gran número de países, constituyen un tipo de política preventiva muy importante y su justificación radica en que son una vía para incrementar el precio de ciertos bienes, para así reflejar los costes sociales asociados con el consumo de estos.

De todas formas, el método alternativo más común para determinar el tamaño del impuesto sobre el carbono es, como ya hemos apuntado, estimar el nivel impositivo necesario para conseguir una determinada reducción de emisiones. Es difícil establecer el impuesto "correcto" con antelación y además, depende del período de tiempo seleccionado y del grado de control requerido. Por ejemplo, el impuesto necesario para estabilizar las emisiones a un nivel en el año 2015 puede ser diferente del impuesto que estabilice las emisiones en otro año (2025). La mayor parte de los análisis económicos sobre las reducciones 
de emisiones de carbono sugieren que los primeros recortes de emisiones (los primeros 15 o 20 años) pueden lograrse prácticamente sin costes -impuestos reducidos-. Pero, a medida que pasa el tiempo, mantener esas reducciones o incluso aumentarlas puede ser cada vez más complicado, por lo que sería necesario un impuesto mayor. No obstante, a medida que pasa el tiempo irán surgiendo alternativas eficientes a los combustibles fósiles, como energías renovables y tecnologías limpias, lo cual tenderá a reducir el impuesto requerido.

Por otro lado, cuando hablamos de la base del impuesto estamos intentando determinar qué es lo que debería ser gravado por el mismo. En ese proceso debemos tener en cuenta los costes marginales de reducir las emisiones (en cuanto se reducirían las emisiones si un euro adicional se gastara en ese cometido). El motivo es que para minimizar el coste total de reducir las emisiones la base del impuesto debe incluir actividades que tengan un bajo coste marginal de reducir emisiones aunque su contribución total a la generación de emisiones sea pequeña. Por ejemplo, si es relativamente fácil reducir las emisiones de metano procedentes de los vertederos puede ser importante incluirlos en la base del impuesto, a pesar de que su contribución a las emisiones no sea muy alta. Lo mismo sería atribuible a otras actividades no relacionadas con los combustibles fósiles (Reilly, et al, 2003).

Por tanto, a la hora de establecer la base del impuesto "óptimo" y teniendo en cuenta la teoría existente al respecto, tendremos que comparar el ahorro de costes administrativos que produce tener una base pequeña con los beneficios en eficiencia que obtendríamos con una base más amplia. La base se establecería de tal forma que el beneficio de una leve ampliación de la base igualara el aumento en los costes administrativos de su ampliación10.

Y hasta aquí la teoría. El análisis de la realidad nos lleva a tener en cuenta otro tipo de consideraciones, tales como la complejidad de intereses políticos que levantaría la ampliación de la base impositiva. Muchos se opondrían a ella. No obstante, la ventaja es que una base más amplia daría lugar a una tasa impositiva más baja en el largo plazo, relajando la oposición frontal al impuesto.

En general, los pocos impuestos sobre el carbono existentes en la actualidad tienen una base más bien estrecha (cinco países escandinavos y Reino Unido). Aunque los primeros impuestos datan de 1991 (Noruega) tampoco tienen una tasa uniforme para las fuentes de emisiones que gravan. Además de no estar armonizadas tampoco son impuestos muy efectivos debido a las numerosas exenciones que tienen. El Reino Unido impuso un impuesto sobre el clima en 2001. La tasa incide en el uso de energía procedente del sector industrial y comercial, quedando exentos el consumo doméstico y el transporte. El tipo impositivo que utiliza es reducido 11 .

10 Ver Metcalf et al (2009). Ofrecen un análisis teórico riguroso respecto a los costes y beneficos de ampliar la base del impuesto sobre el carbono.

$11 \mathrm{El}$ anexo 2 muestra los impuestos sobre el carbono existentes. 
En cuanto al sistema de permisos de emisiones europeo hay que decir que su base no es amplia y que cubre una parte relativamente pequeña de emisiones de gases invernadero. Según Convery et al (2007), la comisión Europea estimó en 2010 que menos de la mitad de las emisiones de CO2 y menos de 1/3 de las emisiones procedentes de otros GEI estaban cubiertos por el sistema europeo de permisos de emisiones. Por ejemplo, el sector de transporte está excluido, aunque la excusa para hacerlo fuera que ya existían impuestos que gravaban la gasolina y otros combustibles de uso automovilístico.

\section{El tipo impositivo}

Un análisis teórico basado en la optimalidad del impuesto es el siguiente:

\section{Gráfico 5: el tipo impositivo óptimo}

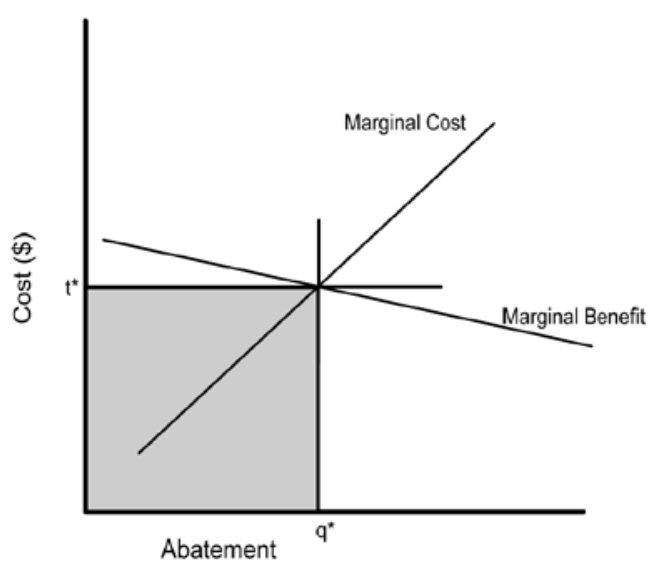

Fuente: Metcalf y Weisbach (2009).

Para establecer un impuesto como el representado en el gráfico 5 el gobierno necesitaría estimar el coste marginal de reducir las emisiones además de estimar también el beneficio marginal derivado de esa reducción de emisiones. Esta, es una tarea no fácil ya que el gobierno o la autoridad competente necesita información acerca del coste marginal y del daño marginal de reducir las emisiones. Trabajos previos (García, C, 2012 y 2013) muestran ejemplos de cómo estimar las curvas de coste y daño marginal así como la dificultad que esta labor entraña, ya que, para ello, hay que disponer de información (sobre costes y daños), cuestión ardua y difícil de conseguir.

Aunque teóricamente el establecimiento de un impuesto sobre el carbono debe cumplir condiciones de eficiencia económica, en la práctica no es tan sencillo, sobre todo la dificultad que tiene el cálculo de los impactos y su traslado a daños marginales. Por ello, en la práctica, muchos analistas (Nordhaus, 2007) estiman un conjunto de impuestos, establecidos a lo largo del tiempo, que tengan la finalidad de cumplir una meta de reducción emisiones o bien que estabilicen las concentraciones totales de carbono de la atmósfera. Esta última 
aproximación tiene dos partes. Una primera que incluye una toma de decisiones acerca de qué nivel de concentraciones de GEl estamos dispuestos a tolerar y una segunda, más técnica, que radica en cómo hacemos para conseguir esto de la mejor forma posible. Claro está que los análisis ofrecen distintos impuestos para cada meta propuesta12.

\section{Gráfico 6: Posibles trayectorias para la reducción de emisiones desde la perspectiva del coste}

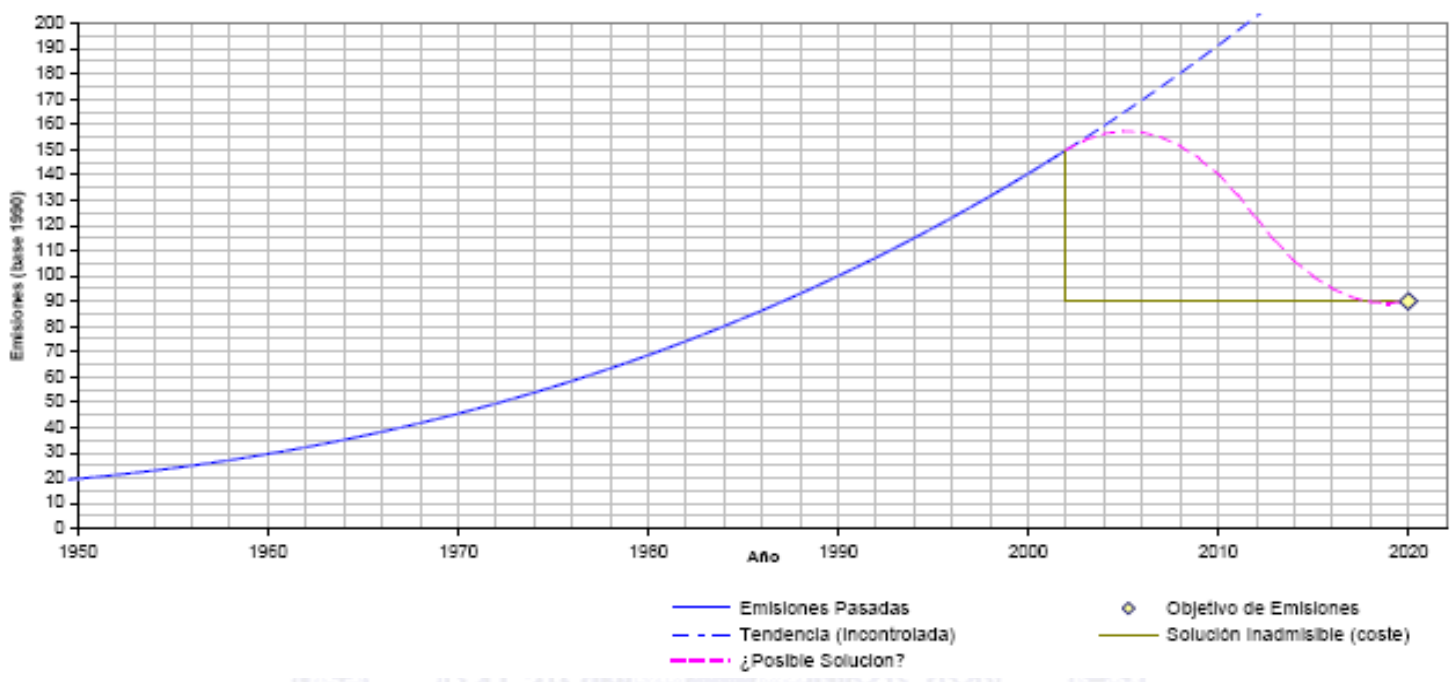

\section{Fuente: elaboración propia}

El gráfico 6 muestra una simulación sobre las posibles trayectorias que puede adoptar la reducción de las emisiones y su correspondencia con los costes que traerían consigo en los distintos casos. La cuestión primordial es que debemos aplicar instrumentos que consigan una reducción gradual de las emisiones ya que, de lo contrario, podríamos incurrir en costes excesivos, perdiendo el objetivo de eficiencia al que hemos hecho referencia. En el gráfico, la trayectoria óptima sería la que apuntamos como "posible solución" ya que conseguiríamos reducir las emisiones de forma gradual (en el año 2020) a un coste mínimo o "coste-eficiencia". Un impuesto gradual podría conseguir esa trayectoria de emisiones sin incurrir en coste muy altos (ver epígrafe "el impuesto gradual").

Varios estudios recientes muestran resultados concluyentes sobre el efecto que distintas tasas impositivas pueden tener en el precio de los combustibles y en la consiguiente reducción de emisiones13. Algunos resultados de los estudios citados pueden verse más abajo. En concreto, Dingell, Stara y Larson en Metcalf, G.E et al (2008) nos muestran estimaciones de distintas tasas impositivas que dan lugar a diversas trayectorias de emisiones. Claramente,

12 El IPCC, en su Working Group II revisa 100 estudios distintos sobre el impuesto óptimo, con un rango de 3 a 95 dólares, estimando una media de 12 dólares por tonelada métrica de CO2 para 2005. (Intergovernmental Panel on Climate Change (2007), p. 16).

13 METCALF, G. E., S. PALSTEV, J. REILLY, H. D. JACOBY, and J. HOLAK (2008): "Analysis of U.S.Greenhouse Gas Tax Proposals," Cambridge: MIT. 
tasas más ambiciosas (Larson) consiguen, a la larga, mayores reducciones de emisiones. Sin embargo, para los primeros 15 años, la aplicación de tasas impositivas distintas no consigue, en general, reducciones importantes. Asimismo, se estudia la incidencia que dichas tasas tienen sobre el bienestar, siendo las mayores pérdidas las relacionadas con tasas más altas (Larson). Dichos estudios también muestran los ingresos obtenidos de la aplicación de diversos impuestos sobre el carbono. Sus estimaciones sobre ingresos para 2015 de impuestos relativamente bajos oscilan entre 69 mil millones de dólares y 126 mil millones. Esto quiere decir que un impuesto de 25 dólares por tonelada métrica de CO2 aumentaría el precio de la gasolina en alrededor de 22 céntimos por galón y el precio del carbón en 2,5 céntimos por $\mathrm{KWh}$. El impuesto sobre el carbono incrementaría además el precio de otras actividades que utilizan la energía como un input intermedio.

Cuadro 1. Distintos tipos impositivos del impuesto sobre el carbono según estudio:

\begin{tabular}{lccc}
\hline & \multicolumn{3}{c}{$\mathbf{C O}_{2}-$ e Price $\left(\mathbf{\$} / \mathbf{t C O}_{\mathbf{2}}-\mathbf{e}\right)$} \\
& Dingell & Stark & Larson \\
\hline $\mathbf{2 0 1 5}$ & 14 & 10 & 20 \\
$\mathbf{2 0 2 0}$ & 14 & 23 & 32 \\
$\mathbf{2 0 2 5}$ & 14 & 34 & 52 \\
$\mathbf{2 0 3 0}$ & 14 & 43 & 83 \\
$\mathbf{2 0 3 5}$ & 14 & 51 & 134 \\
$\mathbf{2 0 4 0}$ & 14 & 58 & 216 \\
$\mathbf{2 0 4 5}$ & 14 & 64 & 348 \\
$\mathbf{2 0 5 0}$ & 14 & 69 & 561 \\
\hline
\end{tabular}

Fuente: Metcalf et al (2008).

El cuadro 1 muestra tres tipos impositivos diferentes. Dingell plantea un tipo constante de 14 dólares por tonelada de CO2 equivalente; Stark estudia los efectos de una tasa que aumenta a lo largo del tiempo pero que va reduciendo su intensidad en los últimos años, mientras que Larson es claramente el más ambicioso, ya que plantea un tipo cuya escalada muestra incrementos cada vez mayores.

Gráfico 7. Representación gráfica de los tipos impositivos 


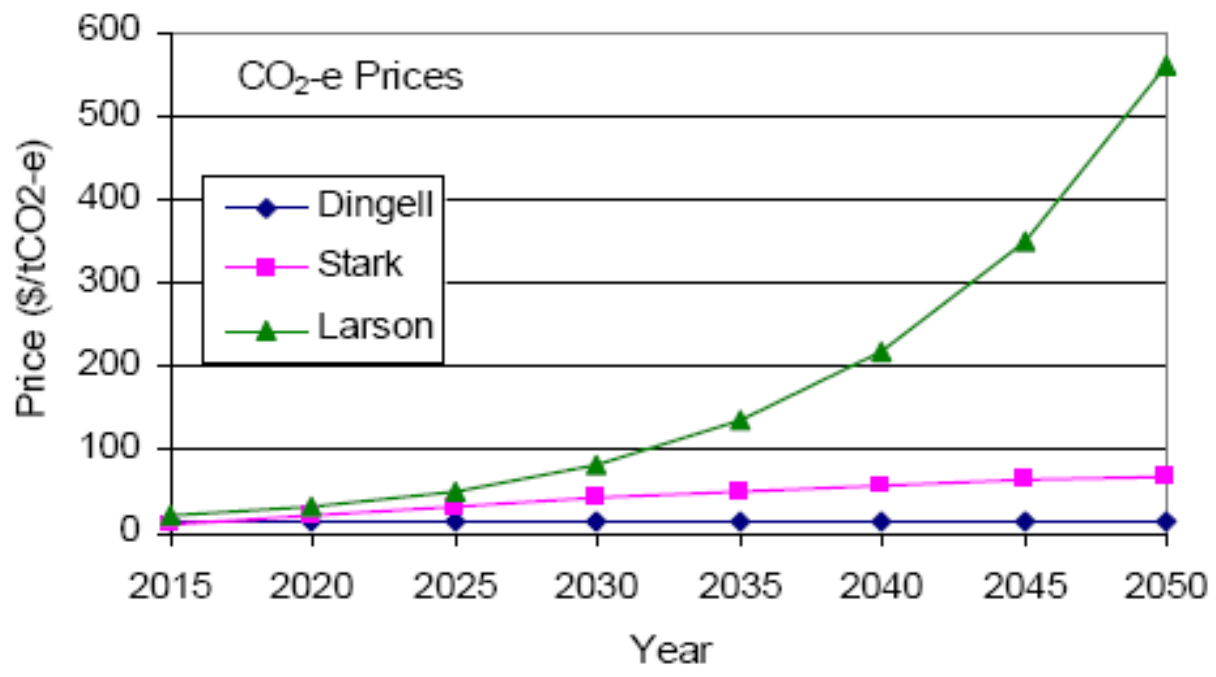

Dichas estimaciones de impuestos sobre el carbono (distintas tasas impositivas) dan lugar a diferentes trayectorias de reducción de emisiones:

\section{Gráfico 8. Trayectorias de emisiones.}

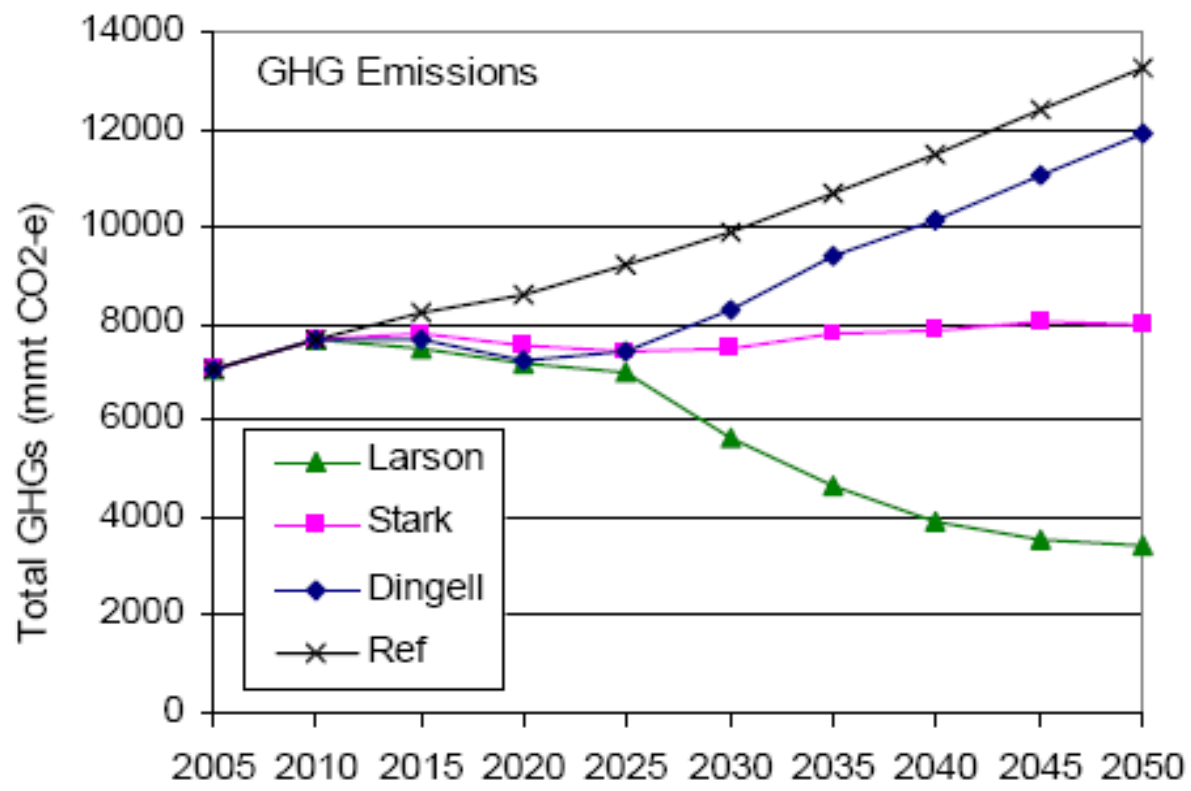

\section{Fuente: Metcalf et al (2008).}

El gráfico 8 muestra como tasas más ambiciosas (Larson) consiguen, a la larga, mayores reducciones de emisiones. Sin embargo, para los primeros 15 años, la aplicación de tasas impositivas distintas no consigue, en general, reducciones importantes.

Dichas estimaciones de la tasa impositiva dan lugar a modificaciones en el bienestar (cuadro 2), medido este por la pérdida de consumo (en el mercado) que acarrea el impuesto y compensado por la ganancia en ocio y tiempo libre que lleva consigo (ocio asociado a pérdidas de empleos): 
Cuadro 2. Cambios en el bienestar producidos por las tasas impositivas.

\begin{tabular}{lccc}
\hline & \multicolumn{3}{c}{ Welfare Changes (\%) } \\
& Dingell & Stark & Larson \\
\hline $\mathbf{2 0 1 5}$ & 0.01 & 0.01 & 0.01 \\
$\mathbf{2 0 2 0}$ & -0.09 & -0.09 & -0.16 \\
$\mathbf{2 0 2 5}$ & -0.25 & -0.27 & -0.24 \\
$\mathbf{2 0 3 0}$ & -0.21 & -0.39 & -0.74 \\
$\mathbf{2 0 3 5}$ & 0.07 & -0.32 & -1.25 \\
$\mathbf{2 0 4 0}$ & 0.21 & -0.38 & -1.71 \\
$\mathbf{2 0 4 5}$ & 0.32 & -0.38 & -2.08 \\
$\mathbf{2 0 5 0}$ & 0.49 & -0.33 & -2.23 \\
\hline $\mathbf{2 0 1 2 - 2 0 1 5}$ & 0.10 & -0.30 & -1.21 \\
\hline
\end{tabular}

Gráfico 9. Representación gráfica de los cambios en el bienestar.

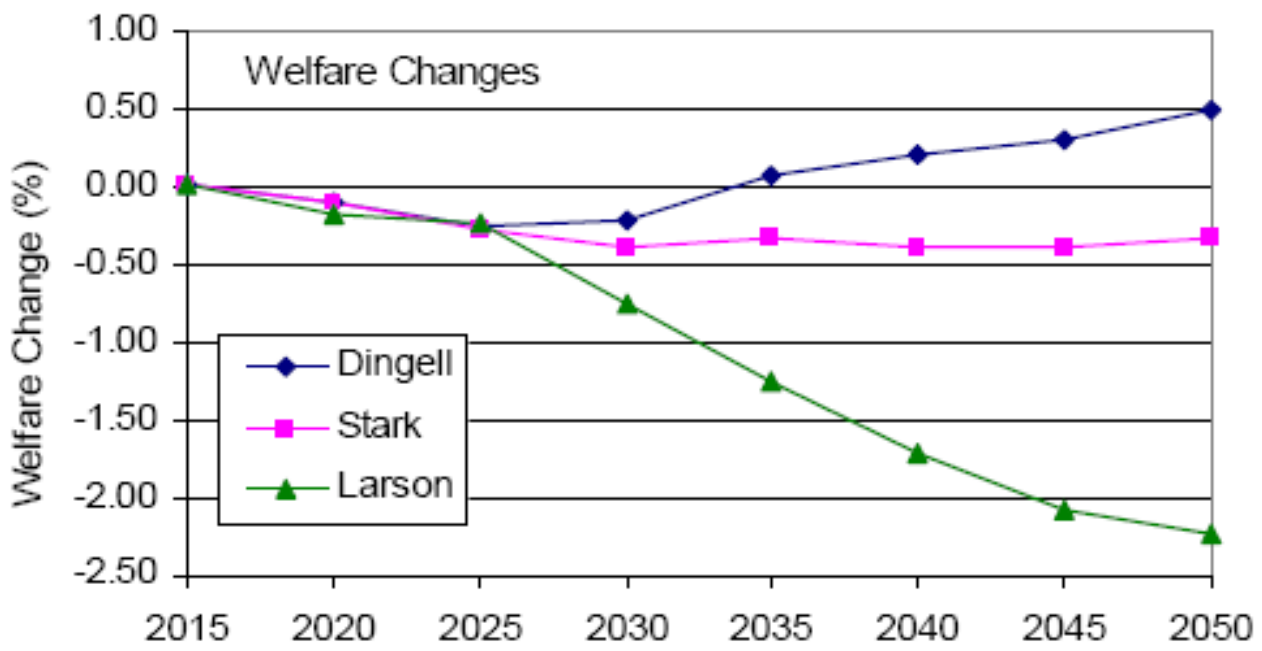

Fuente: Estos resultados pueden encontrarse en Metcalf et al, (2008), donde los autores hacen una interpretación rigurosa del modelo de la EPPA (Emissions Prediction and Policy Analysis). Este modelo puede encontrarse en Paltsev et al (2005) en su versión $n^{\circ} 4$.

El cuadro 2 y el gráfico 9 muestran las pérdidas de bienestar que las distintas tasas impositivas estudiadas podrían generar. No obstante, hay que tener en cuenta que dichas pérdidas podrían amortiguarse utilizando los ingresos del impuesto para compensar a los grupos de población más perjudicados por el establecimiento de dichas tasas. De la misma forma, el reciclaje del impuesto (reducción de otros impuestos que gravan las rentas del trabajo y el capital) ofrece también una medida compensatoria para las rentas más perjudicadas. 


\section{El problema de la elasticidad}

Unos de los efectos más importantes que se derivan del tipo impositivo que finalmente adoptemos es la cuestión de la elasticidad. A la hora de imponer un impuesto sobre el carbono es primordial conocer su magnitud y esta depende de qué tipo impositivo sea el que adoptemos para reducir las emisiones en una cierta cantidad.

Dependiendo de cual sea el tipo impositivo se obtendrán distintos cambios porcentuales en los precios de los combustibles, lo que a su vez, dará lugar a variaciones en el consumo. El instrumento económico que relaciona las variables anteriores es la "elasticidad de la demanda respecto al precio", que es una medida de la sensibilidad del consumo ante cambios en los precios. Para saber qué cambios en los precios serán necesarios para producir una reducción particular del uso de combustibles fósiles necesitamos conocer cuál es la elasticidad de la demanda para esos combustibles, tarea que no es fácil por una serie de razones (Anderson, 1993).

En primer lugar, la elasticidad demanda-precio varía con el período de tiempo considerado. Si, digamos que disponemos de poco tiempo para reaccionar ante un aumento del precio, lo más probable es que mantengamos el mismo comportamiento, soportando, por tanto, el aumento del precio. Es necesario que pase más tiempo para que cambie el comportamiento de los consumidores, por ejemplo, para que se decidan a comprar aparatos domésticos ahorradores de energía.

En segundo lugar, los precios de los bienes afectan a la demanda no sólo de dichos bienes sino también a la de sus sustitutos. Por ejemplo, un aumento del precio del carbón puede abaratar relativamente el petróleo o el gas natural y, por lo tanto, suscitar la sustitución del carbón por estos otros combustibles (el anexo 1 muestra un ejemplo de este caso en particular). El instrumento económico que nos relaciona estas variables es la "elasticidad cruzada de la demanda". Las propuestas de un impuesto sobre el carbono implican simultáneamente a muchas elasticidades de demanda precio y a elasticidades cruzadas, por ejemplo: un aumento del precio del carbón afectará a la demanda de petróleo y gas natural (aumentándolas) y a la suya propia (reduciéndola); un aumento del precio del petróleo afectará a la demanda de carbón y gas natural, etc.

En tercer lugar y de gran importancia está la tecnología, esto es, que exista la posibilidad de introducir cambios tecnológicos más eficientes. Por ejemplo, un alto tipo impositivo sobre el carbono puede ser un incentivo para que una empresa sustituya su método de producción por otro menos contaminante. Pero puede ocurrir que ese nuevo método no exista cuando se impone el impuesto por primera vez, así que, prever cuál es el efecto del impuesto depende de que sea posible prever si el desarrollo tecnológico tendrá lugar o no al menos en un período no demasiado prolongado, lo que le permitiría a la empresa poder sustituir su tecnología contaminante por otra más eficiente. 
Obviamente, en el largo plazo este problema desaparece, ya que existirá la posibilidad de combinar la tecnología avanzada con el impuesto.

Una cuarta cuestión es que el impuesto afectará al precio antes del impuesto, ya que los productores aceptarán alguna disminución de sus márgenes comerciales (con una posible reducción del precio de venta) antes que aceptar una caída de sus ventas. El tipo porcentual del impuesto no se traslada netamente a un incremento porcentual idéntico del precio. Si los márgenes comerciales disminuyen, entonces el incremento del precio debido al impuesto será menor que el tipo impositivo.

Si conociéramos la respuesta de la demanda ante un incremento del precio del combustible podríamos calcular la reducción de emisiones asociada a un impuesto sobre el carbono dado. Todo lo que tendríamos que hacer sería calcular los cambios en el consumo de cada combustible asociados al impuesto (carbón, petróleo y gas natural), multiplicar estos cambios por el peso relativo apropiado de las emisiones (porcentaje de emisiones correspondiente a cada combustible) y sumar los resultados de los tres combustibles. Pocos autores han hecho algún intento de calcular las elasticidades de la demanda de energía, ya que no son fáciles de estimar ${ }^{14}$. Además, no hay garantía de que las estimaciones basadas en datos históricos sirvan para predecir futuras respuestas

En realidad, las elasticidades deberían utilizarse para predecir la respuesta de la demanda ante cambios pequeños en los precios. Si sólo se tienen en cuenta estos efectos e ignoramos otros factores importantes dentro del análisis podría verse qué ocurre cuando los cambios en los precios son grandes, ya que lo que se pretende es tener una idea de la respuesta de la demanda de energía cuando se impone el impuesto bajo distintos supuestos.

El anexo 1 de este trabajo muestra la incidencia que tiene un impuesto de 27 dólares por tonelada de $\mathrm{CO} 2$ equivalente tanto en los precios de los distintos combustibles como en el consumo de estos. Se observa un encarecimiento relativo del carbón y una consecuente reducción en su consumo a favor de un incremento en el consumo del gas natural y del petróleo, fruto de la mayor elasticidad cruzada entre el precio del carbón y la demanda de estos dos combustibles.

\section{Equidad y distribución}

14 Barret (1991) presenta para el Reino Unido las estimaciones hipotéticas de las elasticidades de demanda de energía y las cruzadas, así como el impuesto sobre el carbono necesario para reducir las emisiones en un 20\%. Las elasticidades de demanda fluctuan entre $-0,5$ y -2 , mientras que las cruzadas fluctuan entre 0,1 y 0,75. Por ejemplo, una elasticidad de demanda del carbón de -0,5 significa que un incremento del $1 \%$ en el precio del carbón reducirá la demanda de ese combustible en un 0,5\%. De igual modo, una elasticidad del precio cruzada entre carbón y petróleo de 0,1 significa que un incremento del 1\% en el precio del carbón aumentará la demanda de petróleo en un 0,1 por ciento. 
El impuesto sobre el carbono es regresivo. Para evaluar los efectos distributivos que ocasiona un impuesto sobre el carbono hay que tener en cuenta una realidad importante, y es que las personas de renta inferior suelen gastar en energía una proporción mayor de su gasto total que los grupos de renta más altos, soportando, por tanto, una mayor carga relativa del impuesto. Esto, aunque puede constituir un argumento contra el impuesto sobre el carbono se debilita por los motivos siguientes:

En primer lugar, dado que la sociedad desea hacer algo para reducir las emisiones de gases invernadero, la comparación a tener en cuenta no es el bienestar de una persona o familia con o sin el impuesto, sino con el impuesto y alguna otra política que reduzca, a su vez, las emisiones. Un impuesto sobre el carbono es regresivo, pero también lo son muchas de las alternativas disponibles para reducir las emisiones de gases invernadero. Por ejemplo, cuando se establecen estándares de eficiencia energética para vehículos, aparatos eléctricos, etc, estamos adoptando una medida más bien regresiva, ya que los propietarios de estos aparatos, que suelen tener mayor nivel de renta, pagarán, a la larga, facturas energéticas más bajas. Sin embargo, la investigación económica muestra que la gente pobre prefiere comprar menos accesorios energéticos eficientes debido a su reducida capacidad adquisitiva, por lo que, el consumo de productos menos eficientes les producirá facturas mayores.

La segunda, es que el ingreso anual de una familia es un mal indicador de su bienestar actual. En vez de evaluar los efectos del impuesto en base a los ingresos y gastos anuales en energía de los consumidores que, efectivamente muestran la regresividad del impuesto (los pobres gastan una fracción mayor de su renta en energía), debería escogerse el gasto total en consumo como indicador de bienestar (Poterba, 1991). El motivo es que los ingresos familiares pueden variar de un año a otro, tanto por motivos predictibles como no predictibles, sin embargo, el consumo está basado en el ingreso a largo plazo. Algunos estudios realizados para Estados Unidos 15 muestran que cuando se mide el bienestar familiar en base al gasto total en consumo en vez del ingreso anual se reduce la regresividad del impuesto. Esto significa que el gasto total en consumo es un indicador más fiable para medir los efectos redistributivos del impuesto. Esto se debe principalmente a que las familias experimentan cambios transitorios en su ingreso anual - por ejemplo desempleo, enfermedad, etc.- pero sus gastos reflejarán circunstancias económicas a largo plazo antes que condiciones transitorias.

En tercer lugar, el impuesto brindará una serie de ingresos de los que, una gran parte, pueden ser redistribuidos hacia los grupos inferiores de renta. En efecto, el impuesto sobre el carbono tiene el mismo efecto que un aumento del precio de la energía en una economía que dependa íntegramente de las importaciones de energía. Pero además, el impuesto puede generar ingresos sustanciales, dinero que podría destinarse a un buen uso dentro del país. Es

15 El autor James Poterba muestra sus resultados empíricos sobre los efectos redistributivos del impuesto sobre el carbono en referencia al ingreso anual, por un lado, y al gasto total en consumo, por el otro, en Global Warming, Economic Policy Responses, p.79. 
obvio que todos los países tienen impuestos que generan ingresos. El problema de estos impuestos es que suelen dar lugar a distorsiones importantes. Por ejemplo, un impuesto sobre la renta crea desincentivos al trabajo, un impuesto que grave las ganancias procedentes de la inversión genera un incentivo para que los consumidores sustituyan consumo futuro por consumo presente, etc. Estas distorsiones tienen un coste en términos de producto nacional y, por tanto, afectan al crecimiento de la economía16. Un impuesto sobre el carbono corrige estas distorsiones haciendo que los contaminadores paguen los costes medioambientales de sus acciones. El establecimiento de un impuesto de este tipo no sólo ayudaría a proteger el medio natural sino también incentivaría la sustitución de otras fuentes de ingresos (impuestos sobre la renta, sociedades, etc.) que dañan la economía17. Esto es lo que se conoce como "reciclaje del impuesto sobre el carbono".

Otra alternativa sería gastar parte de los ingresos que nos brinda el impuesto en invertir en una economía baja en carbono. Aquí sería necesario recurrir a otras fuentes de ingresos adicionales para reemplazar la tecnología antigua por la nueva de captura y almacenaje de carbono. Estas tecnologías, ya existentes en la actualidad aunque poco explotadas, traerán consigo mayor eficiencia energética y, por tanto, menores emisiones. La desventaja es que es que son necesarios recursos de inversión importantes.

La opción quizás que tiene más seguidores, aunque no la única, es la de mantener la neutralidad del impuesto (ingresos y efectos distributivos neutrales). De esta forma los ingresos del impuesto se destinarían a reducir otros impuestos manteniendo la progresividad (el impuesto sobre el carbono no cambia la progresividad del sistema impositivo) 18 .

\section{Un impuesto gradual}

Un aspecto fundamental acerca del impuesto sobre el carbono es sobre si se introduce de forma gradual a lo largo del tiempo y así se va aumentando su tasa, e incluso su base, o si se introduce una tasa alta desde el primer momento, sin dar opción a un período transitorio de adaptación. Otra opción barajada es que, en una primera fase, las emisiones (hasta un límite determinado) queden exentas del impuesto, por ejemplo, un nivel de emisiones que iguale a las de un año de referencia. La introducción de una tasa elevada desde el primer momento tiene la doble desventaja de los costes administrativos y de reducción de emisiones que acarrea y de la dificultad de

16 Según Dower y Reppeto (1990), estas distorsiones suponen un coste de entre un 4-7 por ciento del PNB en Estados Unidos.

17 Barker y Lewney (1990) compensan una bajada del IVA con los ingresos obtenidos del impuesto sobre el carbono. Además, también observan que el impuesto no tiene efectos negativos notables sobre el crecimiento. Puesto que el impuesto que ellos establecen es bastante alto, de aquí se deduce que las ganancias de eficiencia derivadas de la reducción del IVA también deben ser grandes.

18 Metcalf, G. E. (2007) ofrece un ejemplo basado en este argumento. 
que sea políticamente factible. No obstante, algunos estudios defienden esta aproximación (ver Metcalf, et al, 2008). El motivo de su defensa es que maximizaría el llamado "efecto de anticipación". Si las empresas entienden y tienen en cuenta que el impuesto se introducirá sin ningún tipo de consideración transitoria para adaptar las inversiones al nuevo sistema, entonces empezarán adaptándose y ajustando sus decisiones desde el primer momento, anticipándose a los futuros impactos del impuesto sobre sus negocios. No obstante, un impuesto así, con efecto anticipativo, sería tremendamente impopular y muy difícil de consensuar. De hecho, la Unión Europea no ha logrado, hasta la fecha, implantar un impuesto sobre el carbono por falta de consenso y por lo impopular que sería estar cambiando continuamente las leyes sobre la imposición.

Aquí abogamos más por un impuesto gradual, tal y como ya se ha expresado desde el principio. Nuestro argumento es que sería beneficioso un impuesto con un tipo progresivo (poco distorsionante) que no aumentara los costes de forma geométrica, pero que cambiara a lo largo del tiempo y a medida que se van implementando las metas de emisiones. Los estudios mostrados anteriormente en este trabajo (Metcalf et al, 2008) evidencian que, a medio plazo, puede ser necesario aumentar los tipos impositivos, ya que, una vez que se ha conseguido una reducción importante de emisiones en las primeras etapas, sino no hay una cambio en las tasas impositivas, las emisiones pueden incluso aumentar. Finalmente, y una vez que los logros de reducción de emisiones fueran cuantiosos entonces podríamos volver a tipos impositivos bajos e, incluso eliminar el impuesto. Esto es importante, ya que los tipos impositivos deben ir ajustándose a la nueva información sobre los costes y beneficios marginales. Lo natural es que cada vez tengamos mayor y mejor información a medida que la ciencia sobre el cambio climático avanza y las nuevas tecnologías mitigadoras se ponen en marcha. La pregunta del millón es la de con qué frecuencia debemos cambiar las tipos impositivos.

Respecto a esto, la cuestión es clara y es que habrá poco beneficio derivado de ajustar los tipos en el corto plazo ya que la mayoría de las oportunidades para reducir las emisiones están relacionadas con inversiones a largo plazo, como por ejemplo la estructura industrial. En todo caso sería conveniente que hubiera una Institución a la que delegáramos la responsabilidad de establecer las tasas del impuesto.

\section{Imposición en frontera}

Los ajustes de impuestos en frontera tienen sentido cuando nos movemos en un sistema donde los países tienen regímenes impositivos distintos Muchos países no aplican y, quizás no aplicarán nunca, impuestos sobre el carbono. El poder hacer ajustes cuando los bienes son exportados e importados es una solución para que todos los países paguen por el consumo de bienes con contenido en carbono. Cuando los bienes producidos en un país que no impone gravámenes sobre el carbono se importan a un país que sí grava estos productos se produce una ventaja comparativa para los productos no gravados en relación a los que se producen en los países con imposición sobre el 
carbono. Esta ventaja potencial radica en menores costes de producción relativos que tienen los países que no gravan el contenido de carbono. Un ajuste impositivo en frontera consistirá en gravar los productos importados (en función de su contenido de carbono) procedentes de países que no gravan el contenido de carbono. El caso contrario se produce cuando productos gravados previamente se exportan a países que gravan el carbono. En ese caso dichos países deberían tener una compensación en frontera para no incurrir en una doble imposición.

De todas formas, lo más complicado de estos ajustes fronterizos es determinar el contenido de carbono de los bienes importados. Este problema es especialmente importante en el caso de los países no pertenecientes al Anexo I del Convenio Marco sobre Cambio Climático (China y otros países en desarrollo con marcado carácter exportador). Estos países no elaboran regularmente inventarios detallados sobre emisiones de carbono, lo que dificulta enormemente la determinación del contenido de carbono de sus productos exportados. Posiblemente, tampoco aceptarían ponerle un precio al carbono.

Es de esperar, asimismo, que la crisis económica conceda una mayor relevancia a la coordinación internacional de las políticas convencionales de cambio climático. Parece claro que en un contexto de pérdida generalizada de puestos de trabajo y actividad económica, los fenómenos de fuga de emisiones a países sin políticas de cambio climático serán objeto de una atención especial y pueden influir en la definición de las políticas futuras o en la modificación de las actuales (tarifas compensatorias en frontera, sectores exentos, etc.). También es probable que haya cambios significativos en el diseño de mecanismos para la participación de países en vías de desarrollo (particularmente China e India), cruciales para el éxito de cualquier estrategia mundial en este campo. Es posible que las ayudas tecnológicas explícitas jueguen un papel fundamental en este sentido, contribuyendo a justificar el previsible esfuerzo tecnológico del mundo desarrollado y a limitar los efectos de la crisis económica sobre los países con menor capacidad económica (Labandeira, 2011).

\section{Conclusiones}

Un objetivo importante de cualquier política destinada a paliar los efectos nocivos del calentamiento global debe ser que ésta sea coste-eficiente, esto es, que pueda obtenerse la reducción máxima de emisiones para un nivel dado de gasto. Saber si es necesaria la acción preventiva depende de cómo sea la relación entre los costes de evitar las emisiones de gases invernadero y los daños que estos gases pueden ocasionar si continúan sin ser sometidos a ningún control.

Sin un cambio radical de modelo energético, la previsión para dentro de 15 años es que el consumo mundial de energía sea un 60\% superior al actual, con el petróleo y el carbón como fuentes de mayor consumo, y el gas natural el de 
mayor crecimiento, con un renovado crecimiento para la nuclear y ligero incremento de las renovables en valor absoluto.

Ante esta situación se hace necesario un cambio en el modelo productivo acompañado de medidas paliativas que consigan una reducción gradual de las emisiones de carbono. Con el fin de no perder el objetivo de eficiencia un impuesto sobre las emisiones ofrece incentivos fuertes para desarrollar y aplicar nuevas y más limpias tecnologías, consiguiendo, en general niveles de eficiencia mayores que las políticas basadas en el control cuantitativo de las emisiones. De la misma forma, un impuesto bien gestionado y adoptado por una mayoría amplia de países sería capaz de conseguir cotas de eficiencia y eficacia superiores a las que logran los sistemas actuales de permisos de emisones. El impuesto es capaz de conseguir un recorte neto de las emisiones de carbono, ya que las empresas, con el fin de reducir su cuantía, tendrán un incentivo adicional para reducir sus emisiones.

Por último, es preciso tener en cuenta que, el cambio climático constituye uno de los mayores fracasos atribuibles al mercado, fracaso que entra en interacción con otras imperfecciones del mercado. Toda respuesta global eficaz requerirá, al menos, tres elementos de política económica: el precio del carbono, aplicado por medio de impuestos, comercio de emisiones 0 reglamentación; una política de apoyo a la innovación y a la aplicación de tecnologías bajas en carbono; y finalmente, la adopción de medidas para eliminar cualquier barrera a la eficiencia energética e informar, educar y persuadir a los individuos sobre lo que pueden hacer, a nivel individual, para responder al cambio climático. Claramente, el cambio climático exige una respuesta internacional, cimentada sobre una comprensión compartida de objetivos a largo plazo y un acuerdo sobre los marcos para la acción.

\section{REFERENCIAS}

BARRET, S (1991). "Global Warming: Economics of a Carbon Tax", en Pearce, D. et al., (1991). Blueprint 2 ( $2^{\mathrm{a}}$ parte de Blueprint for a Green Economy, 1989). Eartscan Publications Limited, Londres, (pp. 31-51).

BRUVOLL, A., and B. M. LARSEN (2004): "Greenhouse Gas Emissions in Norway: Do Carbon Taxes Work?,”. Energy Policy, 32, 493-505.

CARLSON, C., and G. E. METCALF (2008): "Energy Tax Incentives and the Alternative Minimum Tax," National Tax Journal, 61, 477-491.

CLARK, L. E., J. A. EDMONDS, H. D. JACOBY, H. M. PITCHER, J. REILLY, and R.G. RICHELS (2007): "Scenarios of Greenhouse Gas Emissions and Atmopheric Concentrations, Synthesis and Assessment Product 2.1a.

CLINE, W.R. (1992). The Economics of Global Warming. Institute for International Economics. Washinton DC. 
CLARKE, R., BOERO, G., y WINTERS, L.A. (1996). "Controlling Greenhouse Gases: A Survey of Global Macroeconomic Studies". Bull. Econ. Res., Octubre, 48 (4), pp. 269-308.

COMISIÓN EUROPEA (2011). "A Resource-efficient Europe. Flagship Initiative under the Europe 2020 Strategy". Comunicación de la Comisión Europea $\operatorname{COM}(2011) 21$.

- (2011a): "A Roadmap for moving to a competitive low -carbon economy in 20150". COM(2011) 112/4.

CONVERY, F. J., and L. REDMOND (2007): "Market and Price Developments in the European Union Emissions Trading Scheme". Review of Environmental Economics and Policy, 1, 88-111.

FULLERTON, D., and G. E. METCALF (1998): "Environmental Taxed and the Double-Dividend Hypothesis: Did You Really Expect Something for Nothing?," Chicago-Kent Law Review, 73, 221-256.

GAGO, A; LABANDEIRA, $X$. "Cambio climático. Impuestos y Reformas Fiscales". Estudios de Economía Política, 19 (2011):147-161.

GARCÍA, C (2013). "El cambio Climático: Impuestos sobre el Carbono, Coste y Eficiencia Económica". Publicado en soporte digital por la Universidad Pontificia de Comillas, Congreso Internacional "Desafíos del Cambio Climátco" (25-26 febrero de 2013).

(2011). "El Cambio Climático: los aspectos científicos y económicos más relevantes". Nómadas. Revista Crítica de Ciencias Sociales y Jurídicas | 32 (2011.4)

- (2010). "La Evidencia del Cambio Climático. La necesidad de las Políticas Preventivas". Nómadas (25). Revista Crítica de Ciencias Sociales y Jurídicas.

- (2010). "Los costes de la política de cambio climático: una aproximación teórica". Revista Crítica de Ciencias sociales y jurídicas.

- (2009). "La Economía del Cambio climático: las políticas preventivas y sus costes". Revista CIP-ECOSOCIAL. Boletín ECOS nº 9.

- (2008). "Comparación entre Impuestos sobre el Carbono y Permisos de emisiones en el Marco de la Eficiencia económica: una evaluación teórica". Anales de Economía Aplicada, $\mathrm{n}^{0}$ XXII.

- (2006). "El Análisis coste-beneficio y la dificultad de su aplicación al cambio climático". Revista Estudios de Economía Aplicada.

- (2001). "El cambio climático: análisis de las causas" y "El cambio climático análisis de los impactos". UEM. Ediciones. 
- (1999). "El Cambio Climático: Estado de la Cuestión y Aspectos Científicos". DT 8/99. UEM-CEES Ediciones. Nómadas. Revista Crítica de Ciencias Sociales y Jurídicas | 32 (2011.4)

GRUBB, M (2010). "Copenhagen, back to the future?. In Climate Policy, Vol. 10, núm 2.

INTERNATIONAL ENERGY OUTLOOK (2011). U.S. Energy Information Administration

IPCC (2007a). "Summary for Policymakers", en IPCC, Climate Change 2007: The Physical Science Basis: Contribution of Working Group I to the Fourth Assessment Report of thelntergovernmental Panel on Climate Change (Cambridge: Cambridge University Press, 2007).

IPCC (2007b). "Summary for Policymakers", en IPCC, Climate Change 2007: Impacts, Adaptation and Vulnerability. Contribution of Working Group II to the Fourth Assessment Report of the Intergovernmental Panel on Climate Change, (Cambridge: Cambridge University Press, 2007).

JORGENSON, D.W, y WILCOXEN, P.J. (1990). "The Cost of Controlling US Carbon Dioxide Emissions". Harvard University, Cambridge, MA.

KESICKI, F (2010). "Marginal Abatement Cost Curves for Policy Making-ExpertBased vs Model-Derived Curves". Energy Institute, University College London.

LABANDEIRA, X (2011). "Cambio Climático y Crisis Económica". FEDEA y rede (Universidad de Vigo)

METCALF, G. E., S. PALSTEV, J. REILLY, H. D. JACOBY, and J. HOLAK (2008):

"Analysis of U.S. Greenhouse Gas Tax Proposals," Cambridge: MIT.

METCALF, G. E., S. PALTSEV, J. M. REILLY, H. D. JACOBY, A. GURGEL, A. SOKOLOV, and J. HOLAK (2008): "Analysis of a Carbon Tax to Reduce U.S. Greenhouse Gas Emissions," Cambridge, MA: MIT Joint Program on the Science and Policy of Global Change.

METCALF, G. E., and J. M. REILLY (2008): "Policy Options for Controlling Greenhouse Gas Emissions: Implications for Agriculture,"Choices, 23, 34-37.

METCALF, G.E and WEISBACH D. (2009): "The Design of a Carbon Tax". The Law school of University of Chicago. Working paper $n^{\circ} 254$.

NORDHAUS, W. (2002). "After Kyoto: Alternative Mechanisms to Control Global Warming". Yale University. 
NORDHAUS, W. D. (2007): "To Tax or Not to Tax: Alternative Approaches to Slowing Global Warming,"Review of Environmental Economics and Policy,1,2644.

PALTSEV, S; REILLY, J.M; JACOBY, H.D (2005). "The MIT Emissions Prediction and Policy Analysis (EPPA) Model: version 4. Massachusetts Institute of Technology.

PIGOU, A. C. (1938): The Economics of Welfare. London: Weidenfeld and Nicolson.

POTERBA, J. (1991). "Tax policy to Combat Global Warming: On Designing a Carbon Tax". En Global Warming: Economic Policy Approaches. Editado por Dornbush, R.D. y Poterba, J.M, pp. 72-98. Cambridge, MA:MIT Press.

REILLY, J., H. D. JACOBY, and R. G. PRINN (2003): "Multi-Gas Contributors to Global Climate Change, Climate Impacts and Mitigation Costs," Pew Center on Global Climate Change.

STERN, N. 2006. Stern Review on the Economics of Climate Change. Disponible en www.sternreview.org.uk

STERN, N. (2007): The Economics of Climate Change, the Stern Review. Cambridge, UK: Cambridge University Press

UNFCCC Press release (2010). UN Climate Change Conference in Cancun delivers balanced package of decisions, restores faith in multilateral process. Cancun, México, 11 diciembre de 2010. UNFCCC documentos oficiales: www.unfccc.int.

WHALLEY, J. y WIGLE, R. (2002). " Cutting CO2 Emissions: The Effects of Alternative Policy Approaches"en International Trade and Environment, Judith Dean (ed). Ashgate Publishers.

WILLIAM D. COLLINS, CECILIA M. BITZ, MAURICE L. BLACKMON (2005). "The Community Climate System Model Version 3 (CCSM3)". Journal of Climate, vol, 19.

WORLD RESOURCES INSTITUTE (1995). Informe. The Right Climate for Carbon Taxes: Creating Economic Incentives to Protect the Atmosphere.

WORLD RESOURCES INSTITUTE (2006): "Climate Analysis Indicators Tool, Online Database Version 3.0". World Resources Institute. 


\section{ANEXO I}

Cambios en los precios del combustible asociados a un impuesto de 27 dólares por tonelada de carbono:

\begin{tabular}{rccc}
\hline Fuel & $\begin{array}{c}\text { Base Price } \\
\text { Ave. 2002- } \\
\mathbf{2 0 0 6} \\
\mathbf{( 2 0 0 5 \$ )}\end{array}$ & $\begin{array}{c}\text { Added } \\
\text { Cost (\$) }\end{array}$ & $\begin{array}{c}\text { Added Cost } \\
(\%)\end{array}$ \\
\hline Crude Oil (\$/bbl) & $\$ 40.00$ & $\$ 12.20$ & $30 \%$ \\
Regular Gasoline (\$/gal) & $\$ 1.82$ & $\$ 0.26$ & $14 \%$ \\
Heating Oil (\$/gal) & $\$ 1.35$ & $\$ 0.29$ & $21 \%$ \\
Wellhead Natural Gas (\$/tcf) & $\$ 5.40$ & $\$ 1.49$ & $28 \%$ \\
Residential Natural Gas (\$/tcf) & $\$ 11.05$ & $\$ 1.50$ & $14 \%$ \\
Utility Coal (\$/short ton) & $\$ 26.70$ & $\$ 55.30$ & $207 \%$ \\
\hline
\end{tabular}

Incidencia del impuesto anterior en el consumo de combustibles fósiles:

\begin{tabular}{lcccccccc}
\hline & $\mathbf{2 0 1 5}$ & $\mathbf{2 0 2 0}$ & $\mathbf{2 0 2 5}$ & $\mathbf{2 0 3 0}$ & $\mathbf{2 0 3 5}$ & $\mathbf{2 0 4 0}$ & $\mathbf{2 0 4 5}$ & $\mathbf{2 0 5 0}$ \\
\hline Coal & & & & & & & & \\
$\quad$ Dingell & 0.97 & 0.95 & 0.91 & 0.93 & 0.93 & 0.93 & 0.94 & 0.94 \\
Stark & 0.97 & 0.97 & 0.95 & 0.95 & 0.96 & 0.97 & 0.98 & 0.98 \\
Larson & 0.98 & 0.97 & 0.97 & 0.97 & 0.98 & 0.99 & 1.00 & 1.00 \\
287 bmt & 0.98 & 0.97 & 0.94 & 0.94 & 0.95 & 0.96 & 0.97 & 0.98 \\
Natural Gas & & & & & & & & \\
Dingell & 0.78 & 1.25 & 2.88 & 2.23 & 2.30 & 2.27 & 2.19 & 1.59 \\
Stark & 0.79 & 1.01 & 1.75 & 2.03 & 2.01 & 1.28 & 0.86 & 0.14 \\
Larson & 0.78 & 0.98 & 1.43 & 1.33 & 0.94 & 0.73 & 0.60 & 0.68 \\
287 bmt & 0.73 & 0.98 & 2.14 & 2.52 & 1.85 & 1.49 & 0.73 & 0.14 \\
Crude Oil & & & & & & & & \\
Dingell & 0.78 & 0.67 & 0.07 & 0.02 & 0.55 & 0.60 & 0.70 & 0.71 \\
Stark & 0.74 & 0.76 & 0.53 & 0.58 & 0.74 & 0.74 & 0.75 & 0.71 \\
Larson & 0.81 & 0.81 & 0.66 & 0.61 & 0.72 & 0.78 & 0.84 & 0.88 \\
287 bmt & 0.89 & 0.87 & 0.85 & 0.84 & 0.80 & 0.78 & 0.77 & 0.73 \\
\hline
\end{tabular}

Fuente: Metcalf, G et al, 2008. Analysis of a Carbon Tax to Reduce U.S. Greenhouse Gas Emissions," Cambridge, MA: MIT Joint Program on the Science and Policy of Global Change. 


\section{ANEXO 2}

\section{IMPUESTOS SOBRE EL CARBONO EN EL MUNDO}

\begin{tabular}{|c|c|c|}
\hline Country/Province/Mun. & Tax Name & Enactment \\
\hline Sweden & $\begin{array}{l}\mathrm{CO}_{2} \text { levy on heating and } \\
\text { process fuels }\end{array}$ & 2008 \\
\hline Finland & $\begin{array}{l}\text { Charge on exceeding of GHG } \\
\text { emission limits }\end{array}$ & 2004 \\
\hline \multirow[t]{3}{*}{ Norway } & $\mathrm{CO}_{2}$-tax on mineral products & 1991 \\
\hline & $\begin{array}{l}\text { Environmental tax on } \\
\text { greenhouse gases - HFC and } \\
\text { PFC }\end{array}$ & 2003 \\
\hline & $\begin{array}{l}\text { Tax on } \mathrm{CO}_{2} \text { emissions in } \\
\text { petroleum activities on the } \\
\text { continental shelf }\end{array}$ & 1991 \\
\hline Denmark & Duty on $\mathrm{CO}_{2}$ & 1998 \\
\hline Quebec, Canada & Hydrocarbon Duty & 2008 \\
\hline British Columbia, Canada & Carbon Tax & 2008 \\
\hline $\begin{array}{l}\text { City of Boulder, Colorado, } \\
\text { USA }\end{array}$ & Carbon Tax & $2006^{32}$ \\
\hline $\begin{array}{l}\text { San Francisco Bay Area, } \\
\text { California, USA }\end{array}$ & Carbon Tax on Businesses & $2008^{33}$ \\
\hline $\begin{array}{l}\text { Montgomery County, } \\
\text { Maryland, USA }\end{array}$ & $\begin{array}{l}\text { Carbon Tax on Stationary } \\
\text { Sources }\end{array}$ & $2010^{34}$ \\
\hline
\end{tabular}

